
\title{
R Reserach S Surare \\ High D-glucose levels induce ACE2 expression via GLUT1 in human airway epithelial cell line Calu-3
}

\section{Yoshitaka Wakabayashi ( $\nabla$ wakabayashi-tky@umin.ac.jp )}

Teikyo University School of Medicine

\section{Shin Nakayama}

Teikyo University School of Medicine

\section{Ai Yamamoto}

Teikyo University School of Medicine

\section{Takatoshi Kitazawa}

Teikyo University School of Medicine

\section{Research Article}

Keywords: ACE2, SARS-CoV-2, COVID-19, angiotensin converting enzyme 2, glucose transporters

Posted Date: February 10th, 2022

DOI: https://doi.org/10.21203/rs.3.rs-1319865/v1

License: @ (i) This work is licensed under a Creative Commons Attribution 4.0 International License. Read Full License 


\section{Abstract}

Background: Severe acute respiratory syndrome coronavirus 2 (SARS-CoV-2) enters the host cell by binding to angiotensin-converting enzyme 2 (ACE2) receptors. ACE2 is expressed on human airway epithelial cells. Increased ACE2 expression may be associated with potentially high risk of COVID-19. However, the factors responsible for the regulation of ACE2 expression in human airway epithelial cells are unknown. Furthermore, hyperglycemia is a risk factor for poor disease prognosis. In this study, we investigated the effects of D-glucose on ACE2 mRNA and protein expressions in Calu-3 bronchial submucosal cells. The cells were cultured in minimal essential medium containing different D-glucose concentrations.

Results: After 48 and $72 \mathrm{~h}$ of high D-glucose $(1000 \mathrm{mg} / \mathrm{dL})$ treatment, ACE2 mRNA and protein expressions were significantly increased. ACE2 mRNA expression was enhanced by a D-glucose concentration of $550 \mathrm{mg} / \mathrm{dL}$ or more after $72 \mathrm{~h}$ of treatment. In addition, we investigated the role of glucose transporters (GLUTs) in Calu-3 cells. ACE2 mRNA and protein expressions were suppressed by the GLUT1 inhibitor BAY-876 in high D-glucose-treated Calu-3 cells.

Conclusions: This is the first report indicating that high D-glucose levels induced ACE2 expression via GLUT1 in bronchial submucosal cells in vitro. As hyperglycemia can be treated appropriately, these findings could help reduce the risk of worsening of coronavirus disease 2019.

\section{Highlights}

- SARS-CoV-2 enters the host cell by binding to its receptor, angiotensin-converting enzyme 2 (ACE2).

- ACE2 is expressed in many cell types, including bronchial epithelial cells.

- High D-glucose medium induced ACE2 expression in bronchial epithelial Calu-3 cells.

- Glucose transporter 1 (GLUT1) is expressed in Calu-3 cells, and GLUT1 inhibition decreased ACE2 expression.

\section{Background}

Coronavirus disease 2019 (COVID-19) is an infectious disease caused by severe acute respiratory syndrome coronavirus 2 (SARS-CoV-2) [1]. It has spread rapidly around the world and has been declared a pandemic by the World Health Organization [4]. The case fatality rate is approximately $4 \%$ worldwide. However, fatality rates vary greatly between countries [5]. COVID-19 presents with various clinical features, ranging from asymptomatic to severe acute respiratory syndrome, hyperinflammatory response, and thrombosis [1-3]. Furthermore, COVID-19 can cause acute respiratory distress syndrome and multiple organ failure [1]. Some comorbidities such as hypertension, hyperlipidemia diabetes, and bronchial asthma may also increase COVID-19 severity [1]. 
The presence of diabetes mellitus and individual degree of hyperglycemia are associated with COVID-19 severity and increased mortality [6]. One retrospective cohort study has shown that mean glucose levels in the first 10 days of admission are higher on an average among those who died than those who survived [7]. In addition, patients with COVID-19 and hyperglycemia have a greatly enhanced inflammatory cytokine release or cytokine storm syndrome, which causes acute respiratory distress syndrome and multiple organ failure [8]. These studies indicate that tight control of glucose levels may be a key to prevent severe COVID-19. However, the mechanisms of hyperglycemia-related COVID-19 exacerbation remain unknown.

Angiotensin-converting enzyme 2 (ACE2) is a carboxypeptidase that negatively regulates the reninangiotensin system, which can induce vasodilation by cleaving a single residue from the inactive decapeptide angiotensin I to generate angiotensin 1-9 and degrade angiotensin II [9]. Recent studies have shown that ACE2 also acts as a SARS-CoV-2 receptor [10]. Baker et al. reported that ACE2 expression increased when patients are on mechanical ventilation because of lung alveolar damage, indicating a potential mechanism causing higher COVID-19 mortality [11]. In addition, plasma ACE2 levels in patients with severe COVID-19 in the late phase, are higher than those in patients with influenza [12]. An in vivo study has shown that ACE2 protein levels in the lungs of diabetic mice are elevated compared with those in the lungs of non-diabetic mice [13]. Hyperglycemia is thought to increase SARS-CoV-2 entry in airway epithelial cells through glycation of ACE2 [14] leading to severe symptoms. Therefore, we hypothesized that hyperglycemia induces ACE2 expression in the lungs. In this study, we investigated the effects of hyperglycemia on ACE2 expression in bronchial submucosal cells in vitro.

\section{Materials And Methods}

\section{Cell line and culture}

Calu-3, a human submucosal gland cell line derived from bronchial adenocarcinoma, was purchased from Elabscience Biotechnology Inc. (USA). Calu-3 cells were cultured at $37{ }^{\circ} \mathrm{C}$ with $5 \% \mathrm{CO}_{2}$ in MEM (Nacalai Tesque, Inc., Kyoto, Japan) with 10\% fetal bovine serum (Hyclone, Logan, UT, USA), 100 IU/mL penicillin, and $100 \mu \mathrm{g} / \mathrm{mL}$ streptomycin (Nacalai Tesque, Inc.). The cells were stimulated with different Dglucose concentrations as follows: $100 \mathrm{mg} / \mathrm{dL}$ D-glucose (Nacalai Tesque, Inc.) in MEM (NG) and 1000 $\mathrm{mg} / \mathrm{dL}$ D-glucose in MEM (HG). The medium was changed every alternate day. BAY-876 (Medchemexpress, Monmouth Junction, NJ, USA) was used to inhibit GLUT1.

\section{Total RNA extraction and cDNA synthesis}

Calu-3 cells were seeded at a density of $4 \times 10^{5}$ cells/well in 24 -well plates. After $24 \mathrm{~h}$, the medium was replaced with medium containing different $D$-glucose concentrations (100 and $1000 \mathrm{mg} / \mathrm{dL}$ ) and cultured at $37{ }^{\circ} \mathrm{C}$ with $5 \% \mathrm{CO}_{2}$ for 24,48 , and $72 \mathrm{~h}$. Total RNA was extracted with $180 \mu \mathrm{L}$ Tripure (Roche, Basel, Switzerland) from each well following manufacturer's instruction. Total RNA was reverse transcribed to cDNA with ReverTra Ace ${ }^{\circledR}$ qPCR RT Master Mix (Toyobo Life Science, Osaka, Japan). 


\section{Real-time qPCR}

ACE2 gene expression in Calu-3 cells was examined by real-time qPCR. Glyceraldehyde-3-phosphate dehydrogenase (GAPDH) was used as an internal control. Real-time qPCR was performed on a Roche LightCycler 480 system (Roche Diagnostics) using THUNDERBIRD ${ }^{\circledR}$ SYBR® qPCR Mix (Toyobo Life Science). Reactions were performed in a final volume of $20 \mu \mathrm{L}$ containing $1 \times$ THUNDERBIRD $\circledast$ SYBR $\circledast$ qPCR Mix, $0.3 \mu \mathrm{M}$ of forward and $0.1 \mu \mathrm{M}$ of reverse primers, $7.8 \mu \mathrm{L}$ of distilled $\mathrm{H}_{2} \mathrm{O}$, and $1 \mu \mathrm{L}$ of the cDNA template. The primers used in this study were as follows: For human ACE2, forward, 5'-

CCACTGCTCAACTACTTTGAGCC-3' and reverse, 5'-CTTATCCTCACTTTGATGCT-3'; for GAPDH, forward, 5'GAAGGTGAAGGTCGGAGTC-3' and reverse, 5'-GAAGATGGTGATGGGATTTC-3'; for GLUT1, forward, 5'AAGGTGATCGAGGAGTTCTACA-3' and reverse, 5'- ATGCCCCCAACAGAAAAGATG-3'; for GLUT2, forward, 5'-GTTCATGGTGGCCGAGTT-3' and reverse, 5'-ATTGCGGGTCCAGTTGC-3'; for GLUT3, forward, 5'GTTCCCCTCACTGGATGAAA-3' and reverse, 5'-TATTTGGATGGCTCTCCCAC-3'; for GLUT4, forward, 5'GACTCTGGGTGAAAGGG-3' and reverse, 5'-GGGAAGGCTGAGTGAGA-3'; for Toll-like receptor 4, forward, 5'AAGCCGAAAGGTGATTGTTG-3' and reverse, 5'-CTGAGCAGGGTCTTCTCCAC-3'. The amplification conditions were as follows: denaturation at $95^{\circ} \mathrm{C}$ for $5 \mathrm{~min} ; 45$ cycles of amplification $\left(95^{\circ} \mathrm{C}\right.$ for $10 \mathrm{~s}, 60$ ${ }^{\circ} \mathrm{C}$ for $10 \mathrm{~s}$, and $72{ }^{\circ} \mathrm{C}$ for $10 \mathrm{~s}$ ); and cooling at $50^{\circ} \mathrm{C}$ for $30 \mathrm{~s}$. Relative quantification of target gene expression was determined using LightCycler 480 software according to $\Delta \Delta \mathrm{CT}$-method.

\section{Western blotting}

Lysate samples were isolated from Calu-3 cells using a radioimmunoprecipitation assay lysis buffer (Wako Pure Chemical Industries, Osaka, Japan). Total protein was fractionated using $10 \%$ sodium dodecyl sulfate-polyacrylamide gel electrophoresis and transferred to polyvinylidene fluoride membrane. After blocking with $5 \%$ bovine serum albumin in Tris-buffered saline/0.1\% Tween-20 (TBST) at room temperature for $1 \mathrm{~h}$, the membrane was incubated overnight at $4{ }^{\circ} \mathrm{C}$ with antibodies against ACE2 (1:1000; R\&D Systems, Inc. Minneapolis, MN, USA) and GAPDH (1:2000, Santa Cruz Biotechnology, CA, USA). The membrane was washed three times with TBST and incubated with horseradish peroxidase anti-goat or anti-mouse secondary antibody (DakoCytomation, CA, USA) at $20^{\circ} \mathrm{C}$ for $1 \mathrm{~h}$. After washing three times with TBST, immunoreactive bands were detected using a ChemiDoc XRS+ Image System (BioRad Laboratories, CA, USA). Protein bands were quantified using Image Lab software (Bio-Rad Laboratories).

\section{Immunofluorescence staining}

Calu-3 cells were cultured on cover-glass slides for $72 \mathrm{~h}$. The glass slides were washed three times with phosphate buffered saline (PBS), fixed with $4 \%$ paraformaldehyde (Nacalai Tesque, Inc.) for $15 \mathrm{~min}$ at room temperature, and rinsed with PBS. After blocking with PBS containing $5 \%$ bovine serum albumin for 30 min, fixed Calu- 3 cells were incubated overnight at $4{ }^{\circ} \mathrm{C}$ with primary antibody mouse anti-human ACE2 (1:50; Santa Cruz Biotechnology). After rinsing with PBS, the slides were incubated with anti-mouse immunoglobulin G H\&L (Alexa Fluor ${ }^{\circledR}$ 488; Abcam, MA, USA) in PBS. After rinsing with PBS, slides were 
stained with DAPI (Tokyo Chemical Industry, Tokyo, Japan) for 15 min at room temperature. The cover slides were mounted using Fluoromount (Diagnostic BioSystems, CA, USA), scanned, and photographed using a light microscope (Keyence BZ-X800, Keyence Corporation of America, NJ, USA).

\section{LDH activity assay}

LDH activity was measured to determine the effect of D-glucose concentration on cell viability. Calu-3 cells were plated in 96-well plates $\left(1 \times 10^{5}\right.$ cells/well) and incubated in MEM with different D-glucose concentrations ranging from 100 to $5000 \mathrm{mg} / \mathrm{dL}$. After $72 \mathrm{~h}$, cell viability was evaluated using the Cytotoxicity Detection Kit PLUS (Roche Diagnostics), according to the manufacturer's protocol. Cells cultured in MEM were used as controls. The absorbance was measured at $490 \mathrm{~nm}$, and cell viability was calculated using the following formula:

\section{Statistical analysis}

Significant differences among samples were determined by one-way analysis of variance with post-hoc Tukey's honest significant difference test or Student's t-test with $p<0.05$ indicating statistical significance. A minimum of three samples were tested in three independent experiments. All results are presented as mean \pm standard error of the mean. Data analysis was performed using the SPSS software version 24.0 (IBM, Armonk, NY, USA).

\section{Results}

ACE2 mRNA expression levels in Calu-3 cells grown in high D-glucose medium

We investigated the time dependency of ACE2 mRNA expression in Calu-3 cells; the cells were treated with normal D-glucose (NG) or high D-glucose ( $\mathrm{HG})$ for 24,48 , and $72 \mathrm{~h}$. We used real-time quantitative polymerase chain reaction (qPCR) to determine ACE2 mRNA expression levels. ACE2 mRNA expression levels in HG-treated cells were not significantly different from those in NG-treated cells at $24 \mathrm{~h}$. However, ACE2 mRNA expression in HG-treated cells was significantly elevated at 48 and $72 \mathrm{~h}(p<0.05$, Figure $1 \mathrm{a})$. Further, dose-titration of D-glucose was performed in Calu-3 cells at $72 \mathrm{~h}$. The cells were treated with different D-glucose concentrations [100 (NG), 325, 550, 1000 (HG), and 5000 mg/dL]. Interestingly, ACE2 mRNA expression was significantly enhanced with 550,1000 , and $5000 \mathrm{mg} / \mathrm{dL}$ D-glucose treatments, but not with NG treatment $(p<0.05)$. Additionally, lower D-glucose concentrations did not enhance ACE2 mRNA expression (Figure 1b).

\section{ACE2 protein levels in Calu-3 cells grown in HG medium}

To determine ACE2 protein expression levels after NG or HG treatment, we performed western blotting of cell lysates after 24,48 , and $72 \mathrm{~h}$ of treatment. Protein expression levels in HG-treated cells were elevated compared with those in NG-treated cells at 48 and $72 \mathrm{~h}$, but not at $24 \mathrm{~h}$ (Figure 2a and 2b). 
Human bronchial cells express facultative glucose transporters (GLUTs) [15]. We used real-time qPCR to measure the expression of GLUT1-4 in Calu-3 cells. Toll-like receptor 4 was used as a positive control because it is expressed on the surface of Calu-3 cells [16]. We found that GLUT1 was predominantly expressed in Calu-3 cells. Moreover, GLUT2 and GLUT3 expression levels were strong while GLUT4 expression was not detected (Figure 3a). Further, we used BAY-876, a GLUT1 inhibitor, to evaluate the role of GLUT1 in Calu-3 cells. The cells were treated with NG or HG media for $72 \mathrm{~h}$. In addition, Calu-3 cells were treated with 100 or $500 \mathrm{nM}$ BAY-876 for $72 \mathrm{~h}$. ACE2 mRNA expression was measured using real-time PCR. Interestingly, ACE2 mRNA expression in the HG-treated group was significantly higher than that in the NG-treated group, and it was suppressed with 100 or 500 nM BAY-876 treatment (Figure 3b). In addition, ACE2 protein expression levels, with or without BAY-876 treatment, were determined by western blotting. ACE2 protein expression was inhibited by BAY-876 in Calu-3 cells exposed to HG (Figure $3 \mathrm{C}$ and 3D).

Immunofluorescence staining for ACE2 in Calu-3 cells grown in HG medium

To evaluate ACE2 expression on the Calu-3 cell surface, we performed immunofluorescence staining after $72 \mathrm{~h}$ of NG or HG treatment. ACE2 staining intensity detected in HG-treated Calu-3 cells was higher than that in NG-treated Calu-3 cells. Notably, ACE2 staining intensity was lower in HG and BAY-876treated Calu-3 cells than in HG-treated cells (Figure 4).

\section{Cell viability of HG-treated Calu-3 cells}

The cells were treated with different D-glucose concentrations [100 (NG), 325, 550, 1000 (HG), and 5000 $\mathrm{mg} / \mathrm{dL}$ ] for $72 \mathrm{~h}$ and LDH activity was measured. No statistically significant differences were observed between all groups. These results showed that high glucose medium up to $5000 \mathrm{mg} / \mathrm{dL}$ did not have cytotoxic effects on Calu-3 cells (Figure 5).

\section{Discussion}

We showed that HG levels enhanced ACE2 mRNA and protein expression levels in Calu-3 cells via GLUT1 in a dose- and time-dependent manner.

SARS-CoV-2 enters host cells using viral surface transmembrane spike (S) glycoprotein [17]. The S glycoprotein is cleaved into S1 and S2 subunits [17]. As mentioned above, ACE2 serves as a SARS-CoV-2 receptor. The $S 1$ subunit recognizes and binds to ACE2, and the $S 2$ subunit is responsible for viral fusion and entry into host cells [17].

It is well known that ACE2 is expressed in enterocytes, renal tubules, gallbladder, cardiomyocytes, male reproductive cells, placental trophoblasts, ductal cells, eyes, and vasculature [18]. Moreover, ACE2 expression is lower in the lungs than in these tissues [19]. However, pulmonary ACE2 expression is important in the development of infectious disease and has received extensive attention in recent years, as ACE2 serves as a SARS-CoV-2 receptor [10]. ACE2 is expressed on the surface of human lung airway 
and alveolar epithelial cells [20], and ACE2 expression level is positively correlated with airway epithelial differentiation [21]. In addition, lung ACE2 expression is higher in people with comorbidities, such as cancer, hypertension, diabetes, and chronic obstructive lung disease, thereby increasing their susceptibility to COVID-19 [22]. However, the mechanism underlying the induction of ACE2 expression in the lungs remains unknown.

Calu-3 cells are derived from human bronchial submucosal glands and are generated from bronchial adenocarcinoma [23]. Calu-3 cell line is commonly used in SARS-CoV-2 studies because it reflects the properties of bronchial submucosal glands and secretes airway surface liquid, mucins, and other immunologically active substances [23].

High ACE2 expression has been thought to be a risk factor for COVID-19 severity. Ackermann et al. reported that lung ACE2 expression was higher in patients who died of COVID-19 than that in uninfected control subjects [3]. Kragstrup et al. also reported that elevated baseline plasma ACE2 in patients with COVID-9 was significantly associated with increased disease severity during the 28-day study period [24].

Furthermore, diabetes and hyperglycemia have also been considered as risk factors of severe COVID19 [6]. In patients with COVID-19, higher serum C-reactive protein, interleukin-6, and LDH levels, which correlated with disease severity, were observed in the diabetic group with hyperglycemia than in the nondiabetic group [6,25]. Another study suggested that hyperglycemia was the greatest risk factor for 14-day and 60-day in-hospital mortality among critically ill patients with COVID-19 [26]. It is worth noting that hyperglycemia has been observed not only in diabetic patients with COVID-19, but also in patients without any clinical history of diabetes mellitus. The use of corticosteroids in patients with COVID-19 who require oxygen therapy is recommended in clinical practice [27]. One of the side effects of corticosteroid therapy is increased blood glucose levels [28]. Therefore, hyperglycemia is often observed in patients undergoing corticosteroid treatment for COVID-19 at our facility. Uncontrolled glucose levels are considered a poor prognostic factor, and stringent control of glucose levels is important for the treatment of COVID-19 [29].

Lavrentyev et al. reported that ACE2 mRNA expression levels are upregulated in vascular muscle cells after 2 and $4 \mathrm{~h}$ of high glucose treatment [30]. Our results showed that, in the late phase of high glucose treatment, ACE2 expression in lung cells was enhanced compared with that in vascular muscle cells. This indicates the possibility that a longer time might be required to enhance ACE2 expression after D-glucose stimulation in vivo, and further in vivo research will be required.

D-glucose is transported across mammalian cell membranes through two types of receptors: facilitative GLUTs and sodium-glucose linked transporters [15]. Human airway epithelial cells primarily express GLUTs [15]. GLUTs are divided into three classes according to their sequence similarity. Class 1 consists of GLUT 1-4 and 14, which transport D-glucose [31]. Using real-time qPCR, we confirmed that GLUT1 was predominantly expressed in Calu-3 cells. The role of GLUTs in the airway epithelium is under investigation. However, they might play a key role in airway metabolism and regeneration. Furthermore, human immunodeficiency virus and malaria infections are regulated by GLUT1, but there is no research 
on the relationship between GLUT1 and SARS-CoV-2 infection [32, 33]. We used GLUT1 inhibitor BAY-876 to demonstrate that ACE2 expression is regulated by GLUT1. Thus, GLUT1 might play a crucial role in COVID-19 infection by controlling ACE2 expression; however, further investigation is needed.

It was previously reported that ACE2 expression is induced by cytotoxic stimulation in epithelial bronchial cells in vitro [34]. Hence, we needed to exclude the possibility that the cytotoxicity of high glucose levels reinforced ACE2 expression. Interestingly, LDH levels was not significantly changed in Calu-3 cells after $72 \mathrm{~h}$ of HG treatment compared to NG treatment. These results indicated that glucose levels up to 1000 $\mathrm{mg} / \mathrm{dL}$ were not cytotoxic to Calu-3 cells, and ACE2 expression was enhanced by D-glucose itself, not by D-glucose cytotoxicity.

The limitation of our study is that these phenomena are only observed in vitro, and further in vivo studies are required to understand the correlation between ACE2 expression levels and hyperglycemia. In addition, we did not show a relationship between high glucose-induced high ACE2 expression and susceptibility to SARS-CoV-2.

Normally, fasting blood glucose levels in humans are maintained within a range of $4-6 \mathrm{mmol} / \mathrm{L}$ or $72-$ $108 \mathrm{mg} / \mathrm{dL}$ [35]. MEM contained $100 \mathrm{mg} / \mathrm{dL}$ of D-glucose, and Calu-3 cells cultured in MEM were used as a control group in this study. Hyperglycemia is defined as a blood glucose level greater than $140 \mathrm{mg} / \mathrm{dL}$ [36]. In our study, ACE2 expression in cells treated with more than $550 \mathrm{mg} / \mathrm{dL}$ D-glucose was enhanced compared with that in the control group. When blood glucose in the human body is consistently at this high level, emergent diseases, such as diabetic ketoacidosis or a hyperglycemic hyperosmolar state develop [37]. However, topical D-glucose concentration in the airway and alveoli after corticosteroid use remains unknown.

\section{Conclusion}

We have demonstrated that high glucose levels induce ACE2 expression via GLUT1 in Calu-3 cells. These new findings suggest the possibility that hyperglycemia induces ACE2 expression in the lungs, which worsens COVID-19. Close monitoring and tight control of blood glucose levels by oral medication or insulin treatment might be important for preventing the clinical worsening of patients with COVID-19.

\section{Abbreviations}

ACE2: angiotensin-converting enzyme 2

COVID-19: coronavirus disease 2019

GAPDH: glyceraldehyde-3-phosphate dehydrogenase

GLUT: glucose transporter

HG: high D-glucose 
LDH: lactate dehydrogenase

MEM: minimal essential medium

NG: normal D-glucose

qPCR: quantitative polymerase chain reaction

SARS-CoV-2: severe acute respiratory syndrome coronavirus 2

\section{Declarations}

\section{Ethics approval and consent to participate}

Not applicable.

\section{Consent for publication}

Not applicable

\section{Availability of data and materials}

All data analyzed in the current study are available from the corresponding author upon reasonable request.

\section{Competing interests}

The authors declare that they have no competing interests.

\section{Funding}

Not applicable

\section{Authors' contributions}

All authors have contributed to the manuscript. YW, SN, AY, and TK conceptualized the manuscript. YW wrote the first draft, with inputs from SN, AY, and TK. All the authors have updated the manuscript accordingly. All authors contributed to the revisions and approved the final manuscript.

\section{Acknowledgements}

I would like to thank Dr. Yasuo Ota and Dr. Yusuke Yoshino for their helpful discussions.

\section{References}


1. Stasi C, Fallani S, Voller F, Silvestri C. Treatment for COVID-19: An overview. Eur J Pharmacol. 2020;889:173644.

2. Pollard CA, Morran MP, Nestor-Kalinoski AL. The COVID-19 pandemic: a global health crisis. Physiol Genomics. 2020;52(11):549-57.

3. Ackermann M, Verleden SE, Kuehnel M, Haverich A, Welte T, Laenger F, et al. Pulmonary vascular endothelialitis, thrombosis, and angiogenesis in Covid-19. N Engl J Med. 2020;383(2):120-8.

4. Adil MT, Rahman R, Whitelaw D, Jain V, Al-Taan O, Rashid F, et al. SARS-CoV-2 and the pandemic of COVID-19. Postgrad Med J. 2021;97(1144):110-6.

5. Sorci G, Faivre B, Morand S. Explaining among-country variation in COVID-19 case fatality rate. Sci Rep. 2020;10(1):18909.

6. Lim S, Bae JH, Kwon HS, Nauck MA. COVID-19 and diabetes mellitus: from pathophysiology to clinical management. Nat Rev Endocrinol. 2021;17(1):11-30.

7. Lesniak C, Ong R, Akula MS, Douedi S, Akoluk A, Soomro R, et al. Inpatient glycemic control and outcome of COVID-19 patients: A retrospective cohort. SAGE Open Med. 2021;9:20503121211039105.

8. Ye Q, Wang B, Mao J. The pathogenesis and treatment of the 'Cytokine Storm' in COVID-19. J Infect. 2020;80(6):607-13.

9. Burrell LM, Johnston Cl, Tikellis C, Cooper ME. ACE2, a new regulator of the renin-angiotensin system. Trends Endocrinol Metab. 2004;15(4):166-9.

10. Shang J, Ye G, Shi K, Wan Y, Luo C, Aihara H, et al. Structural basis of receptor recognition by SARSCoV-2. Nature. 2020;581(7807):221-4.

11. Baker SA, Kwok S, Berry GJ, Montine TJ. Angiotensin-converting enzyme 2 (ACE2) expression increases with age in patients requiring mechanical ventilation. PloS One. 2021;16(2):e0247060.

12. Reindl-Schwaighofer R, Hödlmoser S, Eskandary F, Poglitsch M, Bonderman D, StrassI R, et al. ACE2 elevation in severe COVID-19. Am J Respir Crit Care Med. 2021;203(9):1191-6.

13. Roca-Ho H, Riera M, Palau V, Pascual J, Soler MJ. Characterization of ACE and ACE2 expression within different organs of the NOD mouse. Int J Mol Sci. 2017;18(3):563.

14. Al-Kuraishy HM, Al-Gareeb Al, Alblihed M, Guerreiro SG, Cruz-Martins N, Batiha GE. COVID-19 in relation to hyperglycemia and diabetes mellitus. Front Cardiovasc Med. 2021;8:644095.

15. Garnett JP, Baker EH, Baines DL. Sweet talk: insights into the nature and importance of glucose transport in lung epithelium. Eur. Respir. J. 2012;40(5):1269-76.

16. Hauber HP, Tulic MK, Tsicopoulos A, Wallaert B, Olivenstein R, Daigneault P, et al. Toll-like receptors 4 and 2 expression in the bronchial mucosa of patients with cystic fibrosis. Can Respir J. 2005;12(1):13-8.

17. Yang J, Petitjean SJL, Koehler M, Zhang Q, Dumitru AC, Chen W, et al. Molecular interaction and inhibition of SARS-CoV-2 binding to the ACE2 receptor. Nat. Commun. 2020;11(1):4541. 
18. Hikmet F, Méar $L$, Edvinsson Å, Micke P, Uhlén $M$, Lindskog $C$. The protein expression profile of ACE2 in human tissues. Mol Syst Biol. 2020;16(7):e9610.

19. Wang Y, Luo W, Huang L, Xiao J, Li F, Qin S, et al. A comprehensive investigation of the mRNA and protein level of ACE2, the putative receptor of SARS-CoV-2, in human tissues and blood cells. Int J Medical Sci. 2020;17(11):1522-31.

20. Hamming I, Timens W, Bulthuis ML, Lely AT, Navis G, van Goor H. Tissue distribution of ACE2 protein, the functional receptor for SARS coronavirus. A first step in understanding SARS pathogenesis. $J$ Pathol. 2004;203(2):631-7.

21. Jia HP, Look DC, Shi L, Hickey M, Pewe L, Netland J, et al. ACE2 receptor expression and severe acute respiratory syndrome coronavirus infection depend on differentiation of human airway epithelia. J. Virol. 2005;79(23):14614-21.

22. Pinto BGG, Oliveira AER, Singh Y, Jimenez L, Gonçalves ANA, Ogava RLT, et al. ACE2 expression is increased in the lungs of patients with comorbidities associated with severe COVID-19. J Infect Dis. 2020;222(4):556-63.

23. Zhu Y, Chidekel A, Shaffer TH. Cultured human airway epithelial cells (calu-3): a model of human respiratory function, structure, and inflammatory responses. Crit Care Res Pract. 2010;2010.

24. Kragstrup TW, Singh HS, Grundberg I, Nielsen AL, Rivellese F, Mehta A, et al. Plasma ACE2 predicts outcome of COVID-19 in hospitalized patients. PloS One. 2021;16(6):e0252799.

25. Zeng Z, Yu H, Chen H, Qi W, Chen L, Chen G, et al. Longitudinal changes of inflammatory parameters and their correlation with disease severity and outcomes in patients with COVID-19 from Wuhan, China. Crit Care. 2020;24(1):525.

26. Mazori AY, Bass IR, Chan L, Mathews KS, Altman DR, Saha A, et al. Hyperglycemia is associated with increased mortality in critically ill patients with COVID-19. Endocr Pract. 2021;27(2):95-100.

27. Horby P, Lim WS, Emberson JR, Mafham M, Bell JL, Linsell L, et al. Dexamethasone in hospitalized patients with Covid-19. N Engl J Med. 2021;384(8):693-704.

28. Tamez-Pérez HE, Quintanilla-Flores DL, Rodríguez-Gutiérrez R, González-González JG, Tamez-Peña AL. Steroid hyperglycemia: Prevalence, early detection and therapeutic recommendations: A narrative review. World J Diabetes. 2015;6(8):1073-81.

29. Ceriello A. Hyperglycemia and the worse prognosis of COVID-19. Why a fast blood glucose control should be mandatory. Diabetes Res Clin Pract. 2020;163:108186.

30. Lavrentyev EN, Estes AM, Malik KU. Mechanism of high glucose induced angiotensin II production in rat vascular smooth muscle cells. Circ Res. 2007;101(5):455-64.

31. Holman GD. Structure, function and regulation of mammalian glucose transporters of the SLC2 family. Pflugers Arch. 2020;472(9):1155-75.

32. Loisel-Meyer S, Swainson L, Craveiro M, Oburoglu L, Mongellaz C, Costa C, et al. Glut1-mediated glucose transport regulates HIV infection. Proc Natl Acad Sci USA. 2012;109(7):2549-54. 
33. Meireles P, Sales-Dias J, Andrade CM, Mello-Vieira J, Mancio-Silva L, Simas JP, et al. GLUT1-mediated glucose uptake plays a crucial role during Plasmodium hepatic infection. Cell Microbiol. 2017;19(2).

34. McAlinden KD, Lu W, Ferdowsi PV, Myers S, Markos J, Larby J, et al. Electronic cigarette aerosol is cytotoxic and increases ACE2 expression on human airway epithelial cells: Implications for SARSCoV-2 (COVID-19). J Clin Med. 2021;10(5).

35. Giri B, Dey S, Das T, Sarkar M, Banerjee J, Dash SK. Chronic hyperglycemia mediated physiological alteration and metabolic distortion leads to organ dysfunction, infection, cancer progression and other pathophysiological consequences: An update on glucose toxicity. Biomed Pharmacother. 2018;107:306-28.

36. Zhang Q, Zhao G, Yang N, Zhang L. Fasting blood glucose levels in patients with different types of diseases. Prog Mol Biol Transl Sci. 2019;162:277-92.

37. Umpierrez GE, Hellman R, Korytkowski MT, Kosiborod M, Maynard GA, Montori VM, et al. Management of hyperglycemia in hospitalized patients in non-critical care setting: an endocrine society clinical practice guideline. J Clin Endocrinol Metab. 2012;97(1):16-38.

\section{Figures}



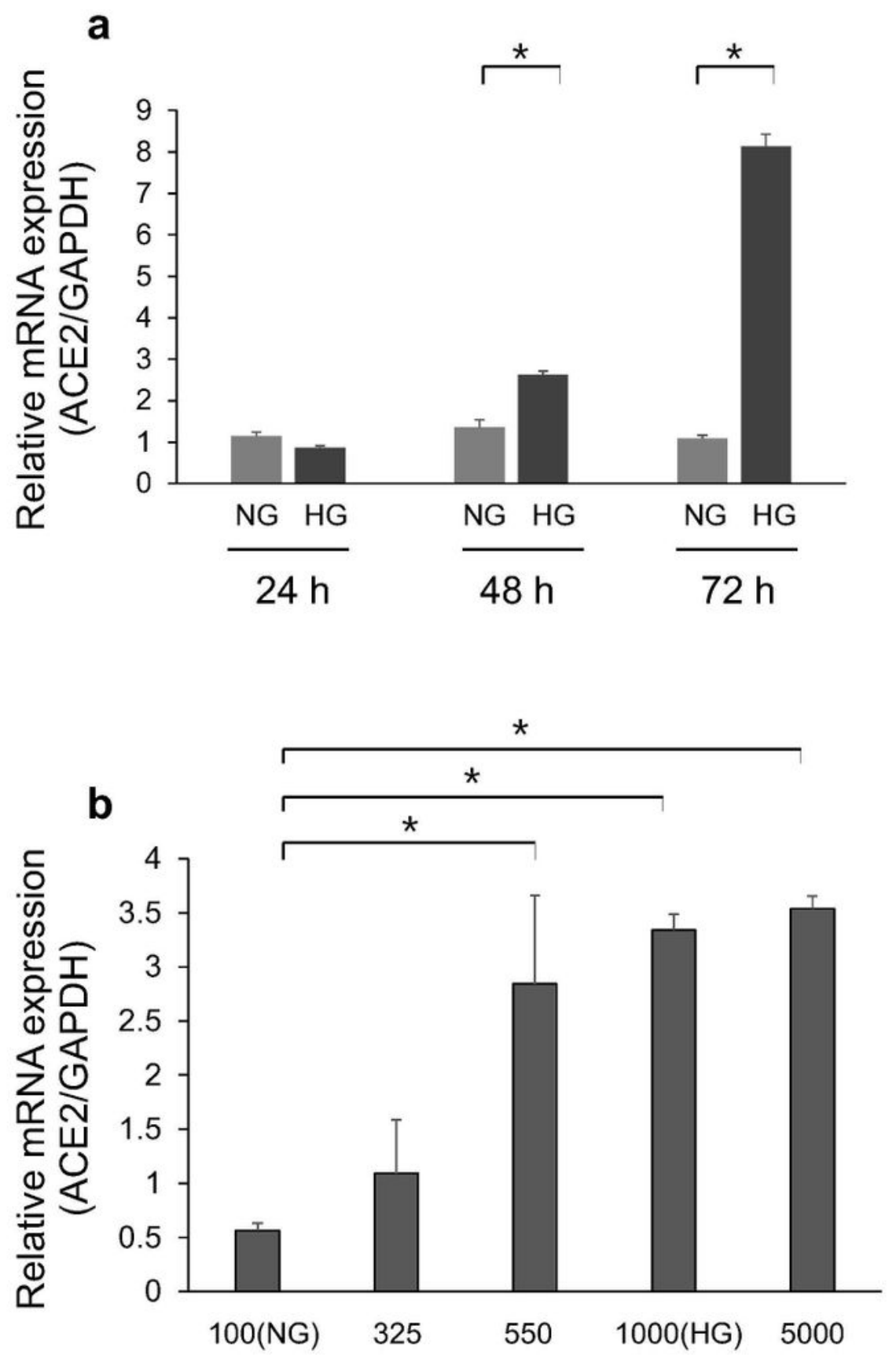

D-glucose concentration ( $\mathrm{mg} / \mathrm{dL})$

Figure 1

Real-time quantitative polymerase chain reaction analysis of angiotensin-converting enzyme 2 (ACE2) mRNA expression. (a) Calu-3 cells were treated with normal D-glucose (NG, $100 \mathrm{mg} / \mathrm{dL}$ ) or high D-glucose (HG, $1000 \mathrm{mg} / \mathrm{dL}$ ) for 24,48 , and $72 \mathrm{~h}$. (b) Calu-3 cells were treated with 100-5000 mg/dL D-glucose concentrations. ACE2 gene expression was normalized relative to the expression of glyceraldehyde-3phosphate dehydrogenase (GAPDH). Data indicated in the graph are mean fold increase \pm SE over mean 
control value. Symbol $(*)$ indicates statistical differences $(p<0.05)$. Data are presented as mean \pm SD ( $n$ $=3)$.

a

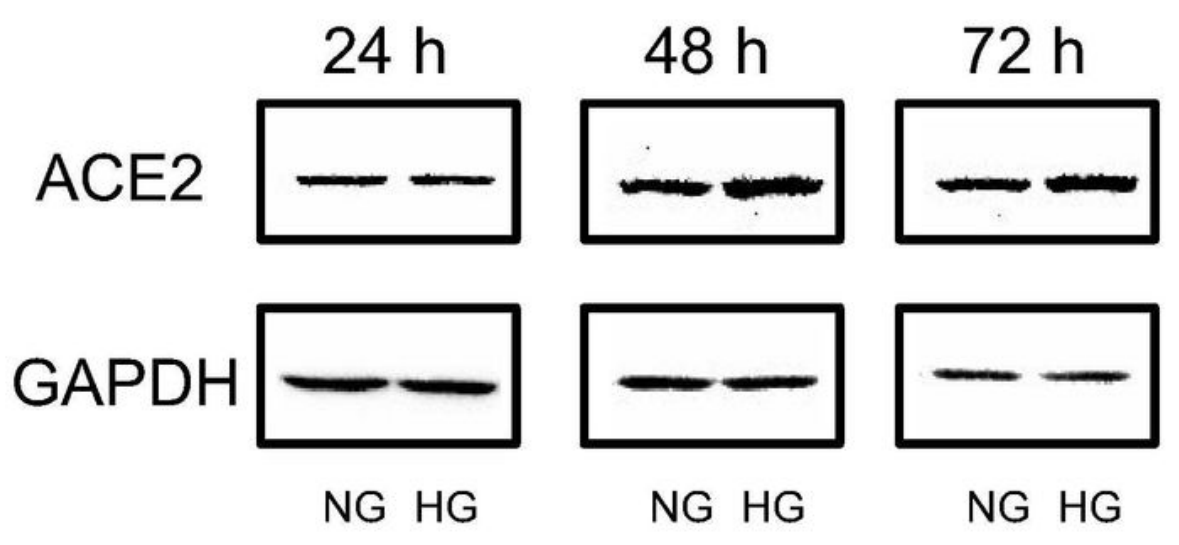

b

$24 \mathrm{~h}$

$48 \mathrm{~h}$

$72 \mathrm{~h}$

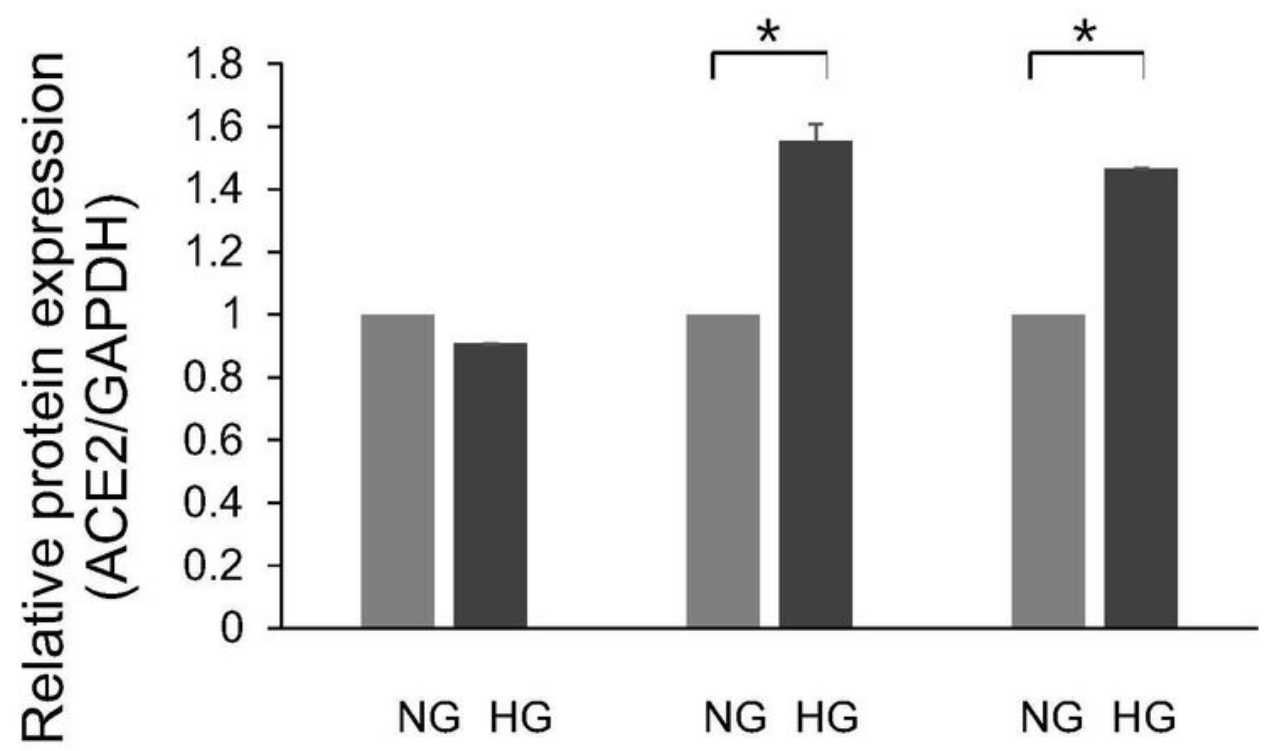

Figure 2

Western blot analysis of angiotensin-converting enzyme 2 (ACE2) expression in Calu-3 cells. (a) The cells were treated with normal D-glucose (NG) or high D-glucose (HG) for 24,48 , and $72 \mathrm{~h}$. Whole cell lysates 
were collected and subjected to western blotting for ACE2 and glyceraldehyde-3-phosphate dehydrogenase (GAPDH). (b) The bar graph was generated by quantifying western blots from three independent experiments. Data are presented as mean \pm SD $(n=3)$. Symbol $(*)$ indicates statistical differences $(p<0.05)$.
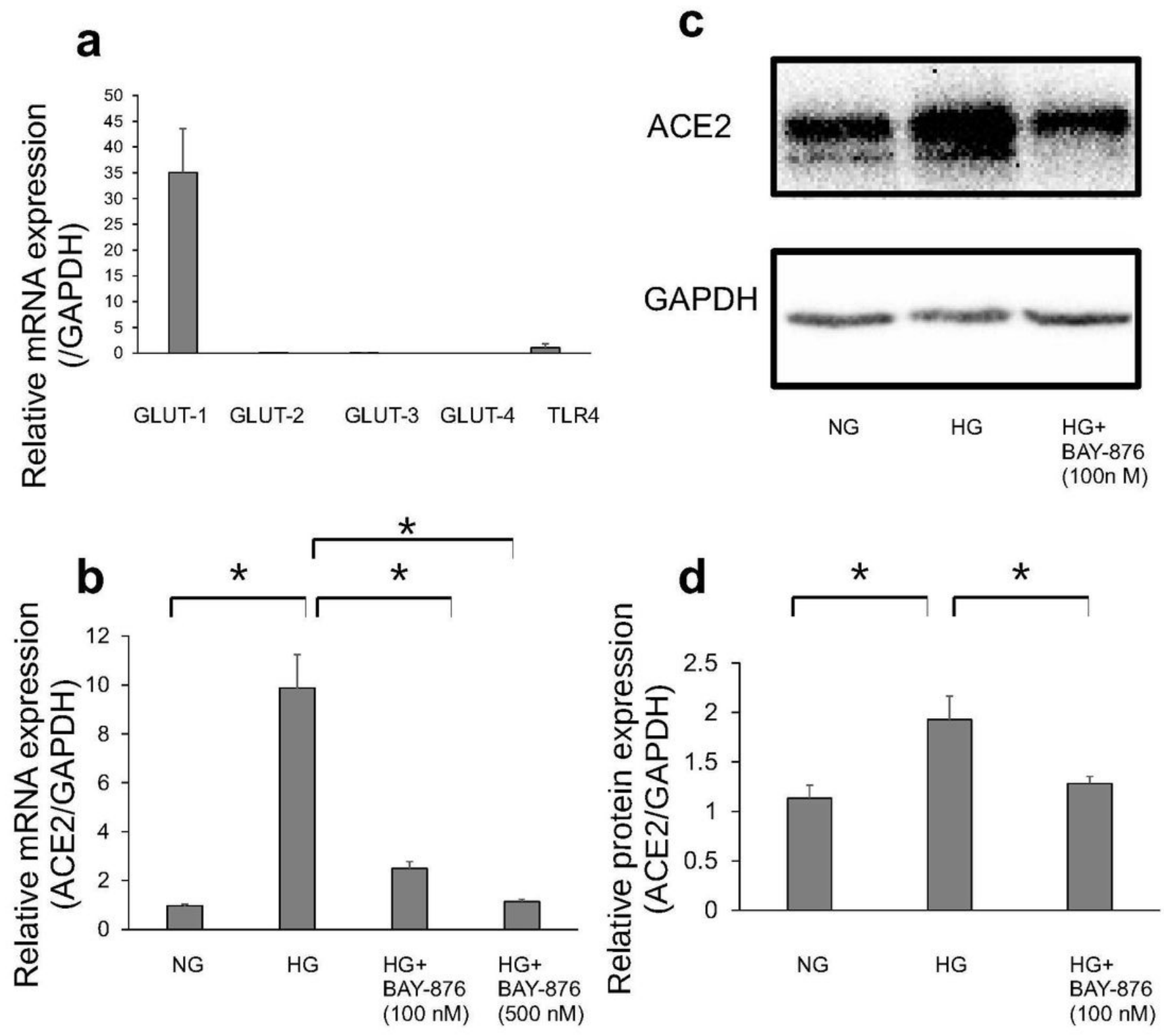

Figure 3

Glucose transporter (GLUT) gene expression levels in Calu-3 cells. (a) Toll-like receptor 4 was used as positive control. GLUT1 was predominantly expressed in the cells. The effects of GLUT1 inhibitor (BAY876) on ACE2 expression were analyzed by real-time PCR (b) and western blotting (c, d) after $72 \mathrm{~h}$ of treatment. Data are presented as mean $\pm \operatorname{SD}(n=3)$. Symbol $(*)$ indicates statistical differences $(p<$ 0.05). 

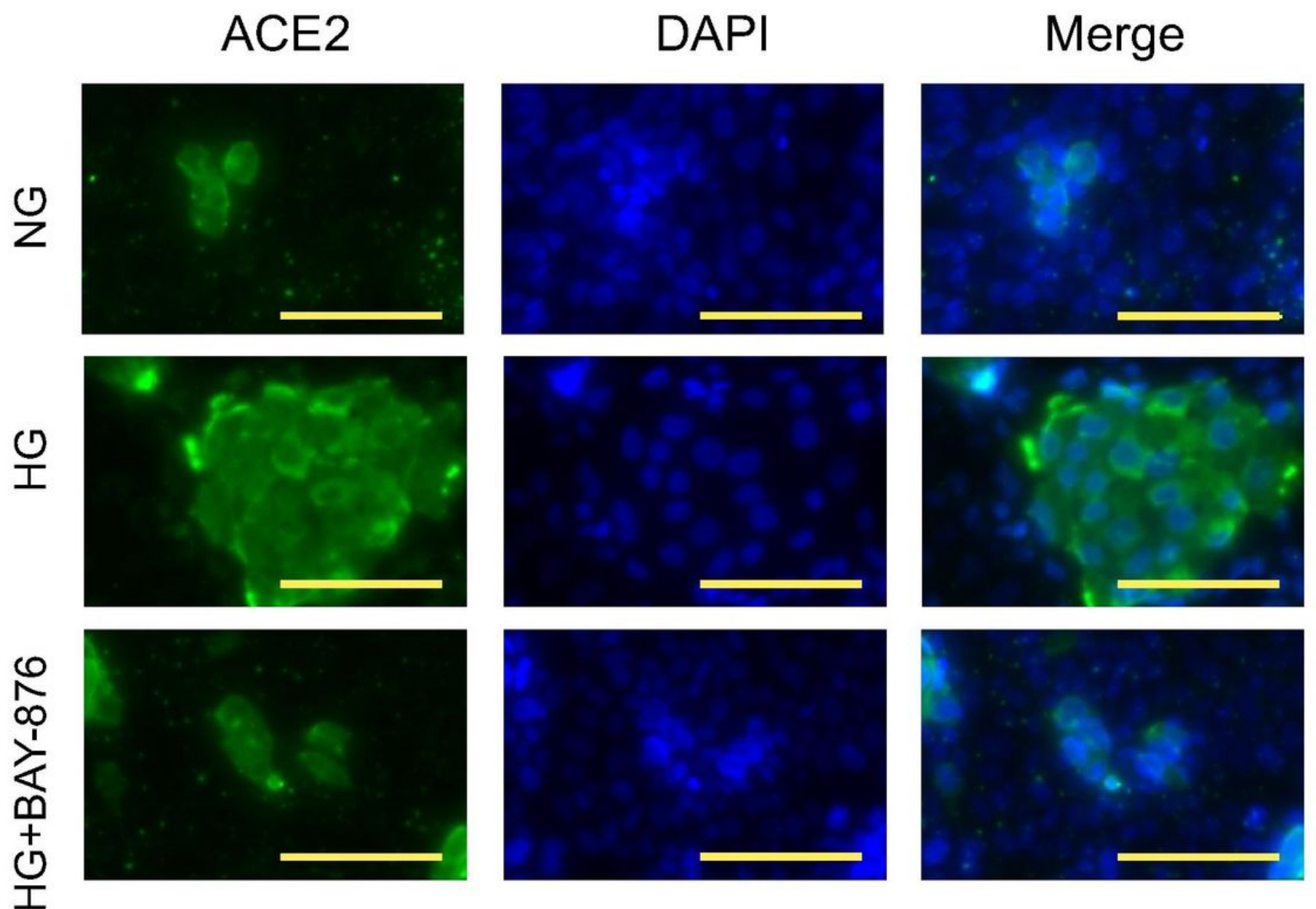

Figure 4

Immunofluorescence analysis of ACE2 expression in Calu-3 cells. The cells were treated with normal Dglucose (NG), high D-glucose (HG), or HG and $100 \mathrm{nM}$ of glucose transporter 1 inhibitor (BAY-876) for 72 h. Green color indicates ACE2 expression, which was enhanced by HG and suppressed by BAY-876 in Calu-3 cells. Nuclei are stained in blue with DAPI. Scale bar, $100 \mu \mathrm{m}$. 


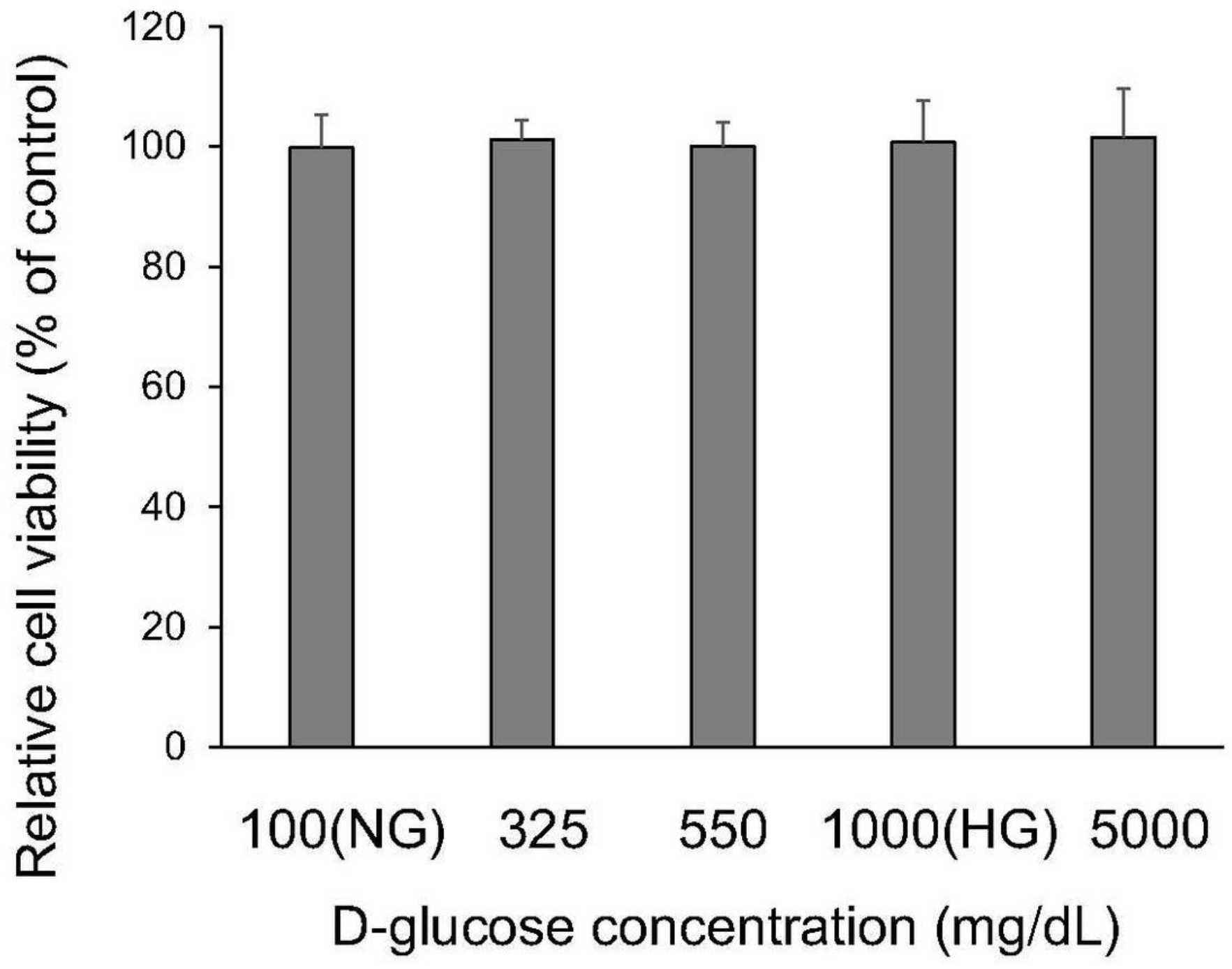

Figure 5

Analysis of Calu-3 cell viability by lactate dehydrogenase assay. Cell viability was measured after the cells were treated with different D-glucose concentrations for $72 \mathrm{~h}$. The figure shows that D-glucose levels did not affect the viability of cultured cells. Data are represented as mean $\pm S D$ ( $n=3$ per group). NG, normal D-glucose; HG, high D-glucose. 